\title{
Competency Needs of Postgraduate Students of STEM Education in Research Writing in Nigerian Universities
}

\author{
Anthonia N. Ugwu' ${ }^{1}$, Florence Obiageli Ifeanyieze' ${ }^{2}$, Philomena Ngozi Agbo ${ }^{3}$ \\ ${ }^{1}$ Department of Science Education, University of Uyo, Uyo, Nigeria \\ ${ }^{2}$ Department of Vocational Teacher Education, University of Nigeria, Nsukka, Nigeria \\ ${ }^{3}$ Department of Educational Foundations, University of Nigeria, Nsukka, Nigeria \\ Email: toniaclare@gmail.com, floraoby2001@yahoo.com
}

Received 1 February 2015; accepted 15 May 2015; published 19 May 2015

Copyright (C) 2015 by authors and Scientific Research Publishing Inc.

This work is licensed under the Creative Commons Attribution International License (CC BY).

http://creativecommons.org/licenses/by/4.0/

(c) (i) Open Access

\section{Abstract}

The study identified research competency needs of postgraduate students of Science Technology Engineering and Mathematics (STEM) education in research writing in Nigerian Universities. The study adopted a survey research design and was carried out in South-Eastern Nigeria. Two research questions and a hypothesis guided the study. The population for the study was $372 \mathrm{com}$ prising 222 master and $150 \mathrm{PhD}$ students of STEM Education in nine Universities in south-eastern Nigeria. Proportionate simple random sampling techniques were used to select $50 \%$ of the population, which gave a sample size of 186 (111 master and $75 \mathrm{PhD}$ students). Structured questionnaire developed from the literature which was reviewed by the researchers was used to collect data. Each item in the instrument had two columns of needed and difficult with each of the columns assigned a four response options with values $4,3,2$ and 1 . The instrument was validated by specialists. Cronbach alpha method was used to determine the internal consistency of the items and a coefficient of 0.85 was obtained. Data collected were analyzed using mean while the null hypothesis was tested using t-test. The findings revealed that postgraduate students needed 32 competencies in research writing; 25 of the competencies were difficult to employ by the students. The hypothesis tested revealed that there was no significant difference in the responses of the two groups of students on the difficult competencies. It was recommended that lecturers should utilize the 32 competencies while emphasizing the 25 difficult ones to make students competent in producing a quality research work.

\section{Keywords}

Research Skill, Competency Needs, Postgraduate Students, STEM Education 


\section{Introduction}

Emergence of knowledge based society with its challenges and demands has increased the urge for research in every sector of life endeavour. Research means a methodical investigation into a subject in order to discover facts about it (Redmond, 2008). Research is the logical, systematic and objective collection, analysis, synthesis, evaluation and recording of accurate and controlled observations for the development of generalizations, principles or theories that are ultimately aimed at description, explanation, prediction and control of natural phenomena to meet specific needs of man (Kpolovie, 2010). In the context of this study, research is a systematic, scientific investigation aimed at finding a solution to an identified problem. That is, it is an action directed towards collection, analysis and interpretation of data on competency needs of postgraduate students in research writing in Universities with a view to making them competent in thesis writing in their various institutions. Research is carried out in many areas of study including education. Ali (2006) defines educational research as a systematic scientific investigation involving identifying ways and means of solving problems relating to teaching and learning so that the goals of education can be attained. Keeres in Onwu (2004) states that research writing involves creation, diffusion and utilization of new knowledge through processes or mechanisms with the aim to link it to its relevant use. Research writing is a pre-requisite for the award of a degree to postgraduate students in universities.

Postgraduate students are individuals who are furthering their studies in universities after obtaining the bachelor degree. Each student carries out a research into a problem area in their different fields of study. The postgraduate students are in two major groups which are masters and $\mathrm{PhD}$ although there are some students that are taking postgraduate diploma in different areas of education. Each of these groups of students carries out research writing. Research writing is quite rigorous and follows some basic steps requiring certain competencies.

Competency in the view of Klemp (1980) is an underlying characteristic of a person which results in effective and superior performance of a job. Competency according to Krevisky and Jordan (1994) is the ability to possess suitable and sufficient knowledge, skills and experience for carrying out a particular task. Olaitan and Ali (1997) defined competency as the knowledge, skills and attitudes that are required for successful performance of a given task. Spenser in Amusa (2010) states that competency refers to a standardized requirements based on which an individual performs a task properly. Competency therefore means the knowledge, skills and attitudes required by students in research writing for production of a credible thesis.

Research writing requires selection of researchable topic and discussing it based on the standard requirement for solution of an identified problem. A postgraduate student with the help of the supervisor is expected to select a researchable topic, write chapters one to three and propose the work to experts who correct, certify and recommend that the candidate should proceed to the next level (4 - 5). There are five chapters of a thesis which are chapter one comprising the introduction/background of the study, statement of the problem, purpose of the study, significance of the study, research questions, hypothesis and delimitation of the study; chapter two is the review of related literature and chapter three methodology while chapters four and five comprises such areas as presentation, analysis, findings and discussion of the findings in addition to the summary, conclusions and recommendation. The trust of this paper is aimed at students of STEM education who are currently in masters and PhD programme to identify their need areas in writing chapters one to five. Onwioduokit (2003) submits that right from the search for researchable topic through data collection and analysis there are steps/principles and traditions to be followed to ensure that the findings are reliable. That is, without the required competencies in research writing, the findings of a study may be invalid, unreliable and not useful. Unfortunately both students and their supervisors encounter some problems in research writing. This is exhibited in the quality of research work in both published articles and postgraduate thesis. Agbo (2013) in a study on "dearth of quality research observed that research played a critical part in many facet of Nigerian society until late 1990s when it suddenly degenerated. The author quoted President Goodluck Jonathan's speech at a Nigerian University convocation ceremony in 2011; that Nigerian Universities record poorly in international ratings because their authorities pay little attention to quality research. Asim, Kalu and Ekwueme (2004) observe that principles and traditions of carrying out research work are no more followed in both published and unpublished research work. Abonyi (2003) observes that there are some fundamental flaws in experimental research published in the Journal of Science Teachers Association of Nigeria (STAN). The author further states that these flaws pose threats to both internal and external validity of research findings. These observations are indications of deficiencies among STEM education researchers. To guard against such deficiencies, it becomes necessary to find out the research 
competency needs of Postgraduates students of Science Technology Engineering and Mathematics (STEM) education who are researchers so as to equip them appropriately; hence the study.

The major purpose of this study was to identify the competency needs of postgraduate students of STEM education in research writing in Nigerian universities. Specifically, the study sought to identify the competency needs and level of difficulty of postgraduate student in

1) Writing chapters one to three for proposal.

2) Writing chapters four and five of the research work.

\section{Methodology}

The study adopted a descriptive survey research design. The choice was anchored on the fact that the data were collected and analyzed on a small number of people as the representative of the entire population (Uzoagulu, 2011). The population consisted of 372 made up 222 master and $150 \mathrm{PhD}$ postgraduate students of education that are already carrying out research on identified problem area in their different fields in the nine Universities in south-eastern Nigeria. Proportionate simple random sampling techniques were used to select $50 \%$ of the population, which gave a sample size of 186 (111 masters and $75 \mathrm{PhD}$ students).

The instrument for data collection was a structured questionnaire developed from the literature reviewed by the study and termed Research Competency Needs questionnaire (RCNQ). Each item in the questionnaire was divided into two columns of needed and difficult. The needed column was assigned a four response options of Highly Needed (HN); Averagely Needed (AN), Slightly Needed (SN) and Not Needed (NN) with values as 4, 3, 2 and 1 respectively while the difficult column was also assigned a four response options of Very Difficult (VD), Moderately Difficult (MD), Slightly Difficult (SD) and Not Difficult (ND) with values as 4, 3, 2 and 1 respectively. The questionnaire items were validated by five experts; two lecturers from Science Education, University of Nigeria, Nsukka and three lecturers from Science Education Department, University of Uyo. The lecturers were asked to check the suitability of the items for collection of data. The reliability of the instrument was determined using Cronbach alpha method and a coefficient of 0.85 was obtained. Researchers collected data from the respondents with the help of three assistants who were selected based on their familiarity with the study area. The respondents were requested to indicate the degree of competency needed and difficult level in each item. Out of 186 copies of questionnaire distributed, 180 were returned and analyzed (107 masters and $73 \mathrm{PhD}$ ). Mean was used to answer the research questions and standard deviation was used to validate the mean while t-test statistic was used to test the null hypothesis at the probability of 0.05 level of significant and 178 degrees of freedom. Decision was taken on each item as follows; any item with a mean value of 1.50 or above was interpreted as needed $\left(\mathrm{X}_{1}\right)$ /difficult $\left(\mathrm{X}_{2}\right)$ while any item with a mean value below 1.50 was interpreted as not needed or difficult. The null hypothesis of no significant difference was accepted where the t-calculated was greater than 0.05 level of significance and rejected if otherwise.

\section{Results}

The results of the study were obtained from the research questions answered and the hypotheses tested. They were presented in Tables 1-3.

Research Question 1: What are the competency needs and level of difficulty in writing chapters one to three of thesis by the postgraduate students in universities?

Data for answering research question one were presented in Table 1.

Data in Table 1 showed that the mean $\left(\mathrm{X}_{1}\right)$ values of all the 17 items ranged from 2.50 to 3.53 which were above 1.50 , indicating that all the items were needed by postgraduate students in writing of chapters one to three of thesis. Table 1 also showed that the mean $\left(\mathrm{X}_{2}\right)$ values of 15 out of 17 items were above 1.50, indicating that the 15 competency items are difficult for postgraduate student while the remaining two items are not difficult.

Research Question 2: What are the competency needs and level of difficult of postgraduate students in writing chapter four and five of thesis.

Data for answering research question two were presented in Table 2.

Data in Table 2 showed that the mean $\left(\mathrm{X}_{1}\right)$ values of all the 15 items ranged from 2.20 to 3.59 which were above 1.50, indicating that all the items were needed by postgraduate students in writing of chapters four and five of thesis. Table 2 also showed that the mean $\left(\mathrm{X}_{2}\right)$ values of 10 out of 15 items were above 1.50, indicating 
Table 1. Mean ratings of postgraduate students on the competency needs\& difficulty level in writing of chapters one-three of thesis.

\begin{tabular}{|c|c|c|c|c|c|c|}
\hline $\mathbf{S} / \mathbf{N}$ & Items ability to & $\mathbf{X}_{1}$ & SD & $\mathbf{X}_{2}$ & Remark & \\
\hline 1 & Generate a researchable topic & 3.15 & 0.22 & 3.90 & Needed & Difficult \\
\hline 2 & $\begin{array}{l}\text { Chapter one } \\
\text { Write the background of the study coherently }\end{array}$ & 3.53 & 0.19 & 3.87 & , & , \\
\hline 3 & Articulate and state the problem of the study concisely & 3.25 & 0.21 & 3.73 & , & , \\
\hline 4 & State the purpose/objectives of the study & 3.27 & 0.23 & 3.43 & , & , \\
\hline 5 & Identify the beneficiaries and state how they would benefit from the study. & 2.70 & 0.22 & 3.18 & , & , \\
\hline 6 & State the research questions and hypothesis that relate to the study. & 2.79 & 02.1 & 1.52 & , & , \\
\hline 7 & Delimit the study appropriately & 2.83 & 0.22 & 2.51 & , & , \\
\hline 8 & $\begin{array}{l}\text { Chapter two } \\
\text { Review related literature }\end{array}$ & 3.47 & 0.32 & 1.48 & , & Not difficult \\
\hline 9 & Organize literature reviewed & 3.21 & 0.23 & 1.37 & & Difficult \\
\hline 10 & Identify and articulate conceptual and theoretical framework & 3.05 & 0.21 & 3.77 & , & , \\
\hline 11 & Review related empirical studies & 3.45 & 0.25 & 3.56 & , & , \\
\hline 12 & Summarize the reviewed literature & 3.15 & 0.22 & 2.64 & , & , \\
\hline 13 & $\begin{array}{l}\text { Chapter three } \\
\text { Choose appropriate design for the study }\end{array}$ & 3.30 & 0.23 & 1.41 & , & Not difficult \\
\hline 14 & Select appropriate population, sample and sampling technique & 2.50 & 0.19 & 2.73 & , & Difficult \\
\hline 15 & Develop instrument for data collection & 2.85 & 0.22 & 3.45 & , & , \\
\hline 16 & Identify qualified validates for the scrutiny of questionnaire items & 2.73 & 0.22 & 3.11 & , & , \\
\hline 17 & Establish reliability of the instrument & 2.50 & 0.10 & 3.01 & ,, & , \\
\hline
\end{tabular}

Table 2. Mean ratings of postgraduate students on the competency needs \& difficult level on writing of chapters four-five of thesis.

$\mathbf{N}=180$ (73 masters and 107 PhD students)

\begin{tabular}{|c|c|c|c|c|c|c|}
\hline $\mathbf{S} / \mathbf{N}$ & Item statement ability to & $\mathbf{X}_{1}$ & SD & $\mathbf{X}_{2}$ & \multicolumn{2}{|c|}{ Remark } \\
\hline 1 & $\begin{array}{l}\text { Chapter four } \\
\text { Collect data in the field }\end{array}$ & 2.95 & 0.59 & 3.10 & Needed & Difficult \\
\hline 2 & Analyze the data making use of appropriate statistical tools & 3.25 & 1.01 & 3.00 & , & , \\
\hline 3 & Present the data in appropriate tables & 1.20 & 0.68 & 3.30 & , & Difficult \\
\hline 4 & Interpret the data accordingly & 3.00 & 0.98 & 2.85 & , & Difficult \\
\hline 5 & Identify major findings of the study & 2.35 & 0.75 & 1.82 & & , \\
\hline 6 & $\begin{array}{l}\text { Chapter five } \\
\text { Discuss the findings of the study based on specific purposes and } \\
\text { literature reviewed }\end{array}$ & 2.20 & 0.80 & 1.95 & , & , \\
\hline 7 & Draw conclusions from the findings & 2.75 & 0.64 & 2.32 & , & , \\
\hline 8 & Make appropriate recommendations for implementation of the findings & 2.35 & 0.63 & 2.10 & , & , \\
\hline 9 & State the educational implications & 2.95 & 0.51 & 2.70 & , & , \\
\hline 10 & Writer limitations of the study & 2.90 & 0.68 & 1.22 & , & Not difficult \\
\hline 11 & Identify and recommend areas for further research & 3.59 & 1.01 & 1.10 & , & Not difficult \\
\hline 12 & Write references accordingly & 2.98 & 0.84 & 2.95 & , & Difficult \\
\hline 13 & Place the appendix properly & 2.43 & 0.54 & 1.05 & , & Not difficult \\
\hline 14 & Package the work for defense & 2.73 & 0.95 & 2.60 & , & Not difficult \\
\hline 15 & Defend the work confidently & 2.95 & 0.51 & 2.90 & ,, & Not difficult \\
\hline
\end{tabular}


Table 3. t-test Analysis on the mean ratings of the two groups of post graduate students on research competencies that are difficult.

\begin{tabular}{ccccccccc}
$\mathbf{N = 1 8 0}$ & & & & & & \\
\hline Level & $\mathrm{N}$ & 0 & $\mathrm{SD}$ & $\mathrm{Df}$ & Cal.t & Crit. t & $\mathrm{P}>0.05$ \\
\hline Master's degree students & 107 & 2.70 & 0.25 & 178 & 0.39 & 1.96 & 0.05 \\
PhD students & 73 & 2.95 & 0.22 & & & & & \\
\hline
\end{tabular}

that the research competency items are difficult for postgraduate student while the remaining 5 items are not difficult.

$\mathbf{H o}_{1}$ There is no significant difference in the mean ratings of masters and postgraduate students in the research competency items that they found difficult while writing thesis.

Data for testing the hypothesis were presented in Table 3.

Data in Table 3 revealed that the t-calculated value is greater than 0.05 , indicating that there is no significant difference in mean ratings of the two groups of students on the research competencies that are difficult. The null hypothesis of no significant difference was upheld.

\section{Discussion}

The findings of this study revealed that postgraduate students of STEM education need all the research writing competencies identified by the study. This confirms the submission of Onwu (2004) that right from the search of topic through the way data are analyzed and inferences drawn, there are principles and traditions to be followed if the findings are to be of any use to the community. Suffix it to say that all research writing competencies have to be fully employed if any meaningful result is to be made. The findings also showed that some research skills are difficult to grasp and employ. It was found out that 15 out of 17 and 10 out of the 15 research competency item identified were difficult. This is in agreement with the submission of (Abonyi, 2003; Asim, Kalu \& Ekwueme 2004; Agbo, 2013) that there are some fundamental flaws in both published and unpublished research work indicating deficiencies in research writing among researchers. The high mean rating of problem articulation is a confirmation of the findings of Asim, Kalu and Ekwueme (2004) that students are aware of the steps and principles to be followed in research writing but they find most of these steps difficult to cross.

With reference to the null hypothesis, there was no significant difference in the mean ratings of master' degree and $\mathrm{PhD}$ postgraduate students on the research competencies that are difficult which is an indication that research skills acquisition are not dependent on the levels but on the dexterity of purpose and competencies possessed by the researchers. These findings portray threats to STEM education and technological advancement in general since research in STEM education is a basis for growth and development.

\section{Conclusion and Recommendations}

It is the wish of postgraduate students to carry out research writing with ease but the postgraduate students of Nigerian Universities have shown that they are deficient in most research writing competencies. This is because the students indicate that 25 out of 32 competency items identified by this study are difficult. The fact that some research competencies are found difficult by some of them coupled with the fact revealed in the literature on the status of both published and unpublished articles means that research competencies are not well mastered by even some professionals. This recommends that stakeholders of STEM education need to see what can be done in earnest so as to improve the quality of research in the field considering the importance of research in every field of life. Lecturers should inculcate the 32 competencies identified by the study to make students competent in writing quality research. STEM and other research lecturers need to focus on carefully explaining to the researchers on the tenets of the items identified by the respondents to be needed but difficult to help the students understand the requirements at such level(s) and catch up on improving postgraduate thesis writing to correct the observed ills.

\section{Limitations of the Study and Recommendations for Future Research}

The adoption of STEM students only for the population and thus sample limits the inference of the findings of 
this study to the general education and/or Nigerian students. Further studies should be carried out in other areas of education and location in the Nigerian Universities for similarity or deviation of the empirical results of this study for broader inference.

\section{References}

Abonyi, O. S. (2003). Fundamental Flaws in Experimental Research. Journal of Science Teachers Association of Nigeria, 38, 107-111.

Agbo, A. (2013). The Dearth of Quality Research (1). The Nation Newspaper, 30.

Ali, A. (2006). Conducting Research in Education and the Social Sciences. Enugu: Tashiwa Networks Ltd.

Amusa, T. A. (2010). Competency Improvement Needs of Farmers in Cocoyam Production in Ekiti State, Nigeria. Masters Thesis, Nsukka: Department of Vocational Teacher Education, University of Nigeria.

Asim, A. E., Kalu, I., \& Ekwueme, C. O. (2004). An Evaluation of Research Skills Displayed in Unpublished Graduate Thesis and Published Researches in Science Education. 45th Annual Conference Proceedings of STAN, 26-29.

Klemp, G. O. (1980). Assessment of Occupational Competence. Washington DC: National Institute of Education.

Kpolovie, J. (2010). Advanced Research Methods. New Owerri, Imo State: Springfield Publishers Ltd.

Krevisky, J., \& Jordan, L. I. (1994). Webster Encyclopedia Unabridged Dictionary of the English Language. New Jersey: Gramery Book Inc. Publishers.

Olaitan, S. O., \& Ali, A. (1997). The Making of Curriculum. (Theory, Process, Product and Evaluation). Onitsha: Cape Publishers.

Onwioduokit, F. A. (2003). National Standards for Science Educational Research. In T. P. Baiyelo, \& T. Busari (Eds.), Standards for Science and Mathematics Educational Research. Lagos: NASER Academic Press.

Onwu, G. O. M. (2004). A Keynote Address. 45th Annual Conference of Science Teachers Association of Nigeria.

Redmond, W. A. (2008). Encarta Dictionary. http://www.microsoft.com/encarta

Uzoagulu, A. E. (2011). Practical Guide to Writing Research Project Reports in Tertiary Institutions. Enugu: Cheston Ltd. 